EDITORIAL

\title{
Ser médico lejos
}

\section{Be a surgeon faraway}

La aventura, lo desconocido, el desafio cuando somos jóvenes, la conquista y también la búsqueda de uno mismo, nos llevará siempre lejos. Reflexionando en la vida propia, no pocas de las empresas que acometimos están inspiradas en esas intenciones.

Asumimos responsabilidades lejos del amparo académico, incentivados por llevar algo de nuestras especialidades más allá del centro. Pensábamos, alguien tiene que hacerlo y sin ser mesiánicos sentimos esa necesidad que nos movió a las provincias de nuestro Chile. En el camino hubo más de alguien que volvió al amparo de su Alma Mater. Otros nos quedamos y ya han pasado los años.

Enfrentamos todo lo que pudimos, hicimos cosas que ahora no haríamos porque "la prudencia es la derrota de la ancianidad" a la que vamos caminando. No obstante lo anterior, el esfuerzo nos hizo crecer con responsabilidad y presencia las 24 horas del día. Seguramente cometimos errores, pero alguien tenía que asumir esa presencia que reclamaba la sociedad cuando éramos especialistas jóvenes.

Recién llegados, la implementación técnica contrastaba con la felicidad de la población que se sentía ufana por contar con la especialidad tan deseada. Pasó mucho tiempo antes que lográramos reproducir algo de lo que teníamos en el centro, algo de lo que habíamos aprendido cuando éramos becados. En fin.

La formación de un cirujano general es una dificil tarea, tanto por la extensión y complejidad de la especialidad, como por la necesidad de abarcar conceptos quirúrgicos de ramas afines (ginecología, urología, traumatología, etc.).

Con frecuencia se advierte en el ámbito nacional una cierta desconfianza por la actividad quirúrgica de las provincias, lo cual hace que muchos cirujanos jóvenes o post becados enfrenten con temor o desagrado un posible traslado desde los grandes centros quirúrgicos. Sin embargo, en la experiencia del autor la cirugía provinciana ha sido altamente estimulante tanto por la variedad del trabajo, como por la interminable necesidad de enfrentar problemas nuevos.

Es importante mencionar que a menudo se presentan patologías quirúrgicas impostergables que nos obligan a resolver problemas complejos que rara vez se le presentan a un cirujano general en las grandes ciudades, y que requiere de un estrecho trabajo en equipo con otros especialistas afines.

Las provincias adquieren cada vez una estructura cívica más desarrollada, a la vez que la aparición de nuevas fuentes de trabajo y de producción importantes, obligan a los servicios de salud a ofrecer una atención adecuada a problemas que en el pasado sólo se resolvían en la capital. La autonomía actual de las distintas regiones, permite a muchos hospitales relativamente pequeños, una situación presupuestaria a menudo más holgada que la de los grandes hospitales y todo este progreso y descentralización, estimula a muchos médicos a permanecer en provincias, gozando de un desempeño profesional gratificante y de condiciones de vida extrahospitalarias agradables. De alli que en los últimos años se haya hecho evidente una notoria mejoría en el nivel quirúrgico de algunas ciudades alejadas de la capital.

La casuística, la magnitud y especialización de alguna de las operaciones realizadas, demuestran por sí solas, la necesidad de un continuo asesoramiento por parte de cirujanos de mayor experiencia. Pretender que el post-becado realice sólo operaciones de rutina, es condenar a un número importante de pacientes a no recibir tratamiento. 
EDITORIAL

Parece claro que se está configurando una generación de cirujanos de provincia cuyas experiencias obligan a redefinir el rol que estos juegan en la medicina nacional. El autor rinde un tributo de admiración a aquellos pioneros provincianos de la buena cirugía, quienes debieron labrar un dificil camino en hospitales entonces rudimentarios, facilitando enormemente la labor de quienes trabajamos alli actualmente.

Dr. Pedro Pablo Pinto G. Cirujano de Coyhaique, Chile 